\title{
Investigating the Effective Impact of Permanent Pavement in Sustainable Development in Developing Countries (From the Point of View of Material Valuation and Prediction of Performance)
}

\author{
Seyed Masoud Hadian \\ Department of Civil Engineering, Faculty of Civil Engineering, Islamic Azad University, Amol, Iran
}

\section{Email address:}

hadian19@gmail.com

\section{To cite this article:}

Seyed Masoud Hadian. Investigating the Effective Impact of Permanent Pavement in Sustainable Development in Developing Countries (From the Point of View of Material Valuation and Prediction of Performance). American Journal of Construction and Building Materials. Vol. 3, No. 1, 2019, pp. 10-15. doi: 10.11648/j.ajcbm.20190301.12

Received: April 15, 2019; Accepted: May 25, 2019; Published: June 5, 2019

\begin{abstract}
Assuming that the road infrastructure has been implemented in accordance with specifications and standards, poor adhesion between the two layers of asphalt mix can be a significant cause of pavement problems. The general problem observed with the weak adhesion between the layers is the slip failure. Slipping disruption in areas where transport acceleration increases, in areas where acceleration decreases or may occur in bumps. One of the criteria and a test method for measuring adhesion resistance between the hot mix asphalt layers is needed to improve the surface finish. The main objective of this study is to determine the effect of reducing the coefficient of friction between asphalt layers in the displacement of asphaltic layers. Because performing experimental experiments in the country is a deterrent to this goal, the use of analytical and numerical methods has been shown to play an important role in conducting studies. Therefore, in this paper, using vehicle simulation in ABAQUS software and analyzes, it has been found that decreasing the coefficient of friction (adhesion reduction) increases the interlayer deformation, which causes the surface of the pavement to fail. Three different thicknesses for asphalt cladding, including 4, 6, and 7 centimeters, and three different thicknesses for roller concrete layers of 18, 20 and 22 centimeters are used. Modeling and analysis of pavements with finite element method has been performed and the depth of the asphalt and tensile strain slope is calculated at the maximum level. The results show that the type of asphalt mix has a high impact on the amount of sloping and tensile strain at the maximum level. So that under different conditions it is estimated to be about 2-3 times in the amount of rotation at the surface. Also, the amount of groove and strain in the middle of the procedure is increased by a thickness of $11 \%$ the thickness of the roller concrete thickness has not changed, but the surface strain has been reduced by $9 \%$.
\end{abstract}

Keywords: Fracture Failure, Fatigue Cracking, High-rise Pavement, Analysis, ABAQUS Software

\section{Introduction}

A large volume of national capital is spent annually on the design, construction and maintenance of pavement road pavement. Permanent pavement is considered as a special type of high-rise pavement (with a life span of 40 years and upwards). This pavement has a specific layer structure, and each of the layers has a special function. Top-down turbulence is one of the most commonly decaying models and one of the most important reasons for the general failure in the pavement $[1,2]$.

While cracking the asphalt layer is inevitable, the study of crack growth in asphalt pavement is important in order to estimate the appropriate time for reconstruction and improvement of pavement and suitable service for roads and high ways. In such a situation, stress factors can be used as essential parameters for the detection of a rupture failure in a permanent pavement. The pavement layers' thickness is the main parameter in the design of pavements and is in fact one of the objectives of the pavement design. Also, the modulus of elasticity of the pavement layers is one of the main 
parameters in the design of pavement types that can be used to obtain the overall design of the pavement $[3,4]$. Increasing the volume and weight of the traffic axis in roads has caused flexible pavement to not function properly in some ways. Therefore, other options have been considered, one of which is the use of composite pavements in which a rigid layer is used as a basis and a flexible asphalt layer is applied on it. The experience of different countries has shown that combined pavements have had a great performance in hightraffic routes. This kind of pavement has longer life, less noise, greater harmony, higher slip resistance and more load bearing capacity, and requires less maintenance than flexural pavements $[5,6]$.

The implementation of rigid asphaltic coatings reduces the stress gradient stresses and stresses caused by traffic loads in the rigid layer. In this type of pavement, the amount of tensile strain decreases significantly under the asphalt layer the fatigue life of the pavement is high. The rigid layer used in composite pavements can be a simple, armed seamless, continuous reinforced concrete, roller concrete, and low cement concrete, cement stabilized soil or cement stabilized concrete. Due to the many benefits, in the past few decades, this type of pavement has been made in different ways in different countries. In Europe, most composite pavements are built from the beginning with the same structure in which the asphalt pavement is made on a base layer of cementstabilized soil, or rock materials fixed with cement, roller concrete, or cementations concrete (Figure 1) [7, 8].

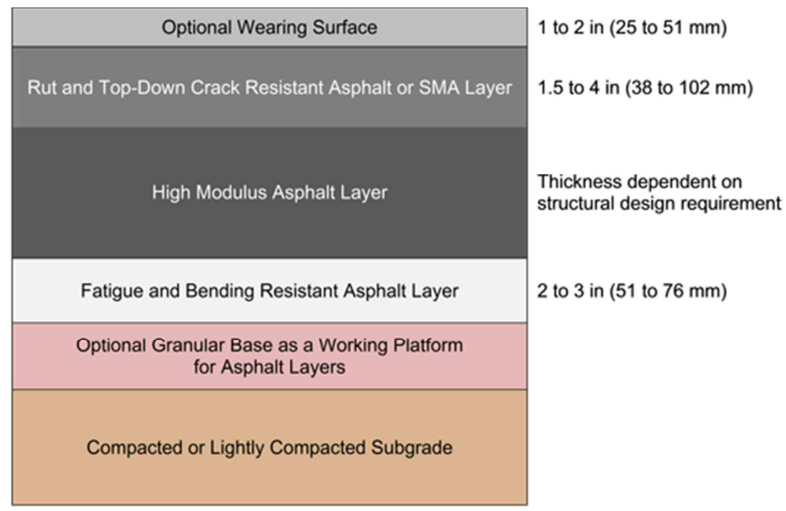

Figure 1. Synthetic pavement structure with asphalt pavement.

Composite pavement in the United States has been further developed to improve the rigid pavement by implementing an asphalt pavement on the concrete pavement, to improve its structural and functional performance [9]. One of the best options for the layered concrete pavement is the roller concrete. Roll concrete is a kind of concrete cement that mixes the coarse and fine stone, cement and water into small amounts. It is made by slipping close to zero with a special finisher for asphalt and compressed with vibrating rollers [10].

One of the important applications of roller concrete is the construction of pavements. The advantages of roller concrete to conventional concrete are the need for mold, armature reinforcement, connecting rod, and timing and seam. This kind of pavement can be implemented in a short time and be exploited by traffic. Another advantage of this kind of pavement is the lack of a need to pay for its surface and durability $[11,12]$.

These features have reduced the cost of the roller concrete pavement compared to conventional asphalt and concrete pavements, and is the ideal option for many applications. Concrete roller bearing is more environmentally friendly and less energy is used in building and operating it. One of the most important uses of roller concrete pavement is the heavy and stationary traffic areas, such as aircraft crashes and creep grips at airports, heavy machinery parking, and access to industrial areas.

One of the problems with these pavements is that after the run, the final level will not have the smooth, roughness and abrasion resistance of fast traffic jams. One solution to this problem is to run a layer of asphalt with a certain thickness on it. This layer will provide the required specifications including panning, comfort, and protection of the roller concrete layer [13].

Combined pavements may cause a variety of failures during their lifetime, which are much like the failure of asphalt pavements. Among the combined pavement failures, three types of failures have been considered: cracking fatigue in the asphalt layer (upwards or downwards) or rigid layer, slope due to plastic deformation in the asphalt layer and Substrate and reflective cracking in asphalt pavement [14].

Reflective cracking is the most common and most critical type of failure in terms of the need for renovation and repair in this type of pavement, which results in cracks in the asphalt layer due to vertical and vertical movements at the site of discontinuity (cracks or seams) in the rigid layer [1516]. The main factors in the reflection cracks in the asphalt pavement are traffic loads and temperature variations. Various methods have been proposed for controlling or reducing these cracks, including the use of georgic and geotextile, the use of crack absorbent layers, and the cutting and sealing of asphalt pavements in the seams [17].

Georgic is the most common type of geosynthetics used to strengthen pavements. Fatigue in asphalt mixtures occurs due to the repetition of tension or strain caused by traffic loads. Fatigue of asphalt mixtures will lead to cracking. Traditionally, leave Fatigue corrosion in low-to-high asphalt pavements Which starts at the bottom of the asphalt layer and extends to the top. However, studies have shown that topdown corrosion is one of the major failures of pavement [18, 19]. Typically, in the asphalt layer, combined pavement topto-bottom cracking because the strain at the bottom of the asphalt layer is usually of a compressive nature, unless there is a connection between the asphalt pavement and the underlying rigid layer. Zhao et al., By comparing fatigue cracking, found two types of pavements, including highstrength fixed pavement, and low-hard-core pavement, which was dominated by a high-low-level pavement with a low-up cracking effect does not have [20].

However, in aggregate-based pavements, low and low cracking occurs at medium and low temperatures, and at high 
temperatures there are high-down cracks. They also showed that by increasing the temperature and thickness of the asphalt layer, the possibility of cracking increases upward. In flexible pavements, the groove in the wheel set occurs due to the accumulation of plastic deformations in the pavement and substrate layers. The slots created in addition to reducing safety and ease of driving will lead to further breakdowns. Combined pavement roughness, although not as flexible as pavement, will be under great effort due to the placement of an asphalt layer on a high-strength layer. The accumulation of plastic deformations in the asphalt layer and the substrate and layers of the undamaged under the rigid layer tends to rupture [21, 22].

Due to the hardness of the concrete layer in the joint pavement, the stresses and strains created in the substrate and the non-stabilized layer of this type of pavement are very low and do not affect the development of this type of pavement, Unless the rigid layer is damaged and cannot properly load the load [23, 24]. Therefore, slope control in this type of pavement greatly affects the quality of materials the coating is coated and the tension is created. As discussed in previous sections of this section, major failures in asphalt pavement are combined pavements including reflective cracks, highdown fatigue, and grooving $[25,26]$. The study of these failures is a matter of varying degrees of need for study that has not been sufficiently investigated. The purpose of this study was to investigate the effects of various factors on two types of fracture failure and high / low fatigue cracking in asphalt treatment using ABAQUS software.

\section{Material and Methods}

\subsection{Material}

As mentioned above, the purpose of this study is to investigate the effect of various factors on the fracture failure and high-down cracks in pavement of asphalt roller concrete. For this purpose, the effect of type of mix, geogrid type and position, thickness of asphalt and roller concrete on grooves and upper to lower cracks in asphalt cladding have been studied.

The effect of 2 types of asphalt mixes with different characteristics including a typical asphalt concrete, two types of coarse-grained mastic asphalt and two types of SuperPio Asphalt concrete on two different failures in this research have been investigated. The reason for using these mixtures, the different types of aggregates, the type of bitumen and the method Mixing plan is in them, the effect of these features will be studied on the failures studied. Also, the effect of three types of geogrid with different mechanical properties, with two different depths including the asphalt and low asphalt pavement thickness two failures are considered. Three different thicknesses for asphalt cladding, including 4, 6 and 7 centimeters, and three different thicknesses for roller concrete layers of 18, 20 and 22 centimeters have been used. Modeling and analysis of pavements with finite element method has been performed and the depth of the asphalt and tensile strain slope is calculated at the maximum level.
In this research, using three-dimensional modeling in ABAQUS software finite element software, sections of the roller concrete pavement with simulated asphalt pavement and pavement responses are obtained under the various conditions mentioned in the previous section and have been analyzed and compared. As described in the previous section, two types of asphalt mixtures with different properties in this study are used as asphalt pavement. These mixtures have different qualities and their application to pave the way to low traffic is very heavy. The difference between these mixtures in aggregates is the quality of bitumen and stone materials and their behavior.

\subsection{Modeling by Means of Finite Element Methods}

In many cases, elastic analysis is used for pavement. In this analysis, materials are considered elastic for each layer, while HMA materials act as elastic only at low temperatures, and at high and average temperatures, elastic theory cannot properly show the deformation properties of asphaltic materials. . In the theory of elasticity, the effect of traffic speeds cannot be considered to be more important at lower traffic speeds. In this section, a comparison between linear elastic model and viscoelastic model is performed to evaluate their relative performance. In the linear elastic model Hooke's law is used to describe the behavior of HMA materials.

Although the materials are elastic and the effect of speed and time cannot be considered, the effect of temperature can be considered by measuring the modulus of resonance at different temperatures. These results were obtained from experiments designed to determine the modulus of resonance at three temperatures of 5, 25 and $40 \mathrm{C}^{0}$ and in 5 different conditions in the laboratory, and it was assumed that the temperature changes with exponential changes. Therefore, the modulus of resonance at any temperature can be obtained with this exponential model. This model is presented in Figure 2 and shows the relationship between temperature and the modulus of oscillation for various materials; also this value was obtained after reviewing 5 states according to Table 1.

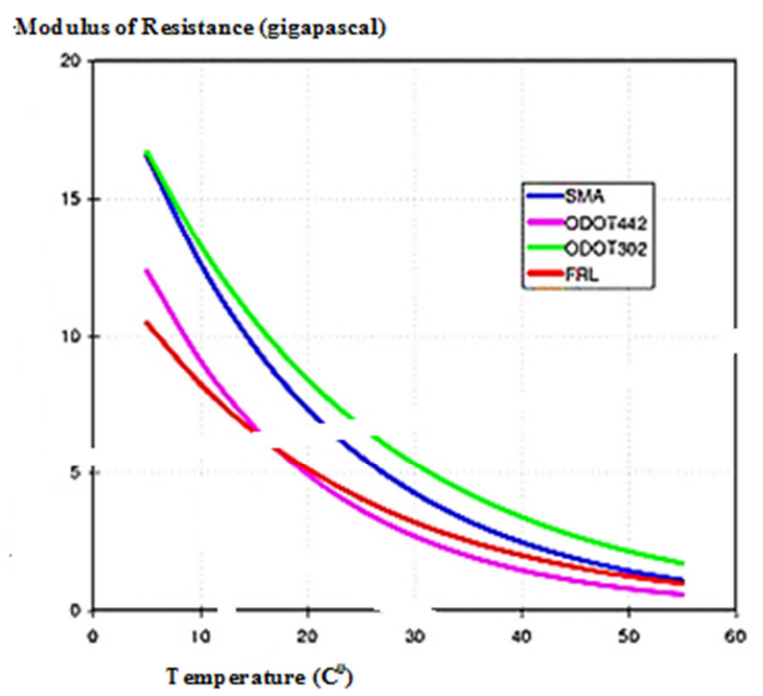

Figure 2. The relationship between temperature and modulus of variation for different materials. 
Table 1. Different thicknesses intended to reach the desired cross section.

\begin{tabular}{llllll}
\hline Layer & Mode 1 & Mode 2 & Mode 3 & Mode 4 & Mode 5 \\
\hline ODOT302 & 9 in & 10 in & 10 in & 10 in & 10 in \\
Base & 6 in & 6 in & 8 in & 10 in & 12 in \\
\hline
\end{tabular}

\section{Findings}

Layer modules are one of two important factors that play a major role in resistance to pavement failures. Theoretically, less thickness is required for pavement if asphalt materials have a higher modulus. In this section, the effect of the modulus of the layers on the longitudinal tensile strain is studied maximally. The three values for the maximum strain strain modulus in Figure 3 are shown and the effect of this change in the values in Figure 4 is shown.

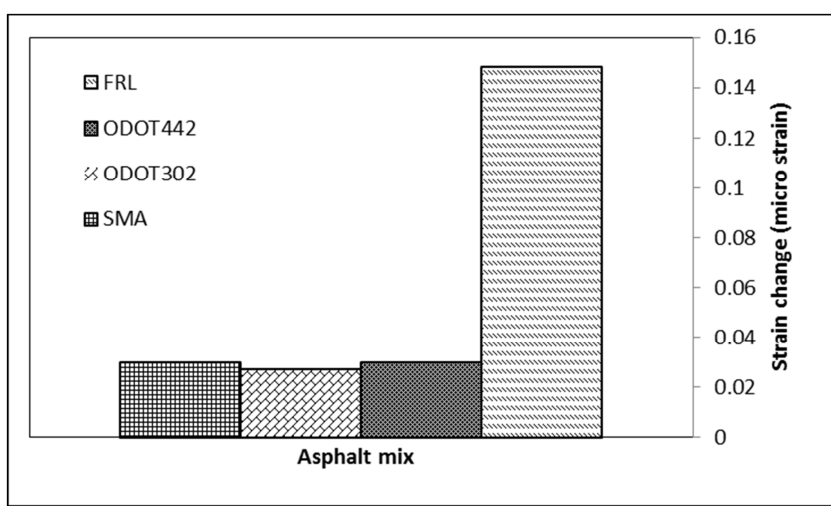

Figure 3. The rate of strain change in different layers resulted from a $30 \%$ reduction in the modulus of the layers.

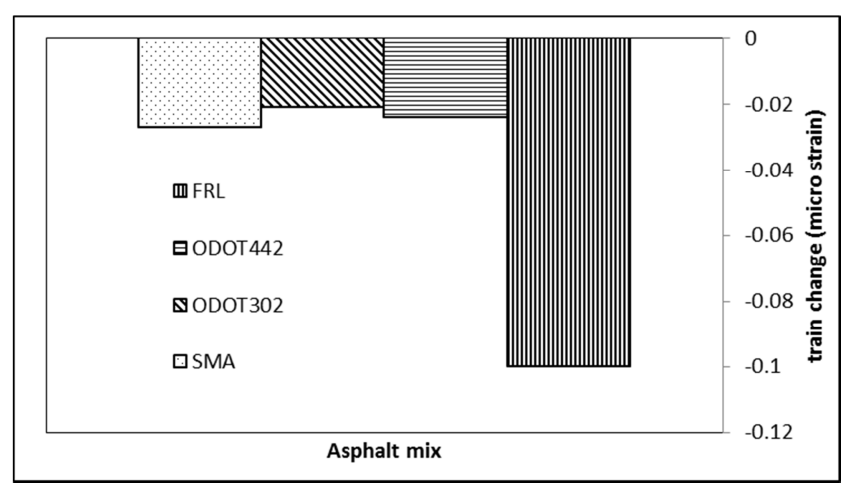

Figure 4. The rate of strain change in different layers is due to a $30 \%$ increase in the modulus of the layers.

According to this Figure 3 and Figure 4, it can be seen that the FRL layer plays the most important role on the maximum tensile strain compared to other layers. With a $30 \%$ increase in the modulus of this layer, the tensile strain decreases from $80.6 \mu \mathrm{g}$ to $70 \mu \mathrm{m}$. This is an effort to increase the elastic modulus to reduce the tensile strain at the bottom of the FRL layer, which is not a good reason for two reasons:

1. Increase in the elastic modulus has little effect on the amount of strain.

2. Fatigue life of asphalt mixtures decreases because they are harder and less flexible.

\section{Discussion}

Flexible pavers are usually not designed for a long time period. The typical life of such pavements is between 18 and 25 years old. With the increasing traffic and traffic growth, road authorities and cities are trying to find a way to extend the road's useful life and minimize drivers' delay and disturb the normal distribution of traffic due to road repairs and rebuilding [27-28]. So, they turned to durable pavements to enhance the useful life of design for up to 50 years and benefit from economic, social and environmental benefits. Following this event, it should be compared economically with the usual pavements used for high traffic volume. The higher initial cost of a permanent pavement than ordinary pavements, as well as the new design of this method, makes the use of this pavement a little doubtful.

The cost drivers of the road include all the costs that the contractor faces during the life of the project. These costs include:

1. Primary Engineering: Costs that are spent on basic studies on design options, licensing, engineering design, and advisory options.

2. Contract execution: The costs incurred for contracting.

3. Elementary construction: Manufacturing costs are related to each option. For example, each different route option on the road and the amount of material should be considered in the analysis.

4. Construction oversight: Costs related to construction oversight, cost of construction management consultancy, material test costs, or other costs related to construction oversight $[29,30]$.

5. Maintenance costs: Includes maintenance costs for acceptable pavement procedures. Information about maintenance costs of everyday reactive type is usually hard to come by. However, these costs are usually small, and usually there is no difference from the restoration option to the restoration option. They have a negligible effect on current net worth (NPV) and are usually discarded. When maintenance costs are considered for options, they should be reported in life cycle analysis $[31,32]$.

6. Basic repair costs: Includes the costs associated with each repair option (usually including re-cover costs). These costs are calculated in the same way as the initial construction costs.

7. Final value of the road: Includes the value of the existing materials, the service life of the route, and so on [33].

\section{Conclusion}

The results of this study showed that while the cost of building a permanent pavement is more than the usual asphalt pavement, in the course of a 50 year period, the life cycle cost analysis calculations show that the durable pavement, in addition to better performance, also has a lower cost. Therefore, durable pavement is economically feasible 
and is a good option. Figure 5 illustrates the life cycle analysis diagram in pavement management [34].

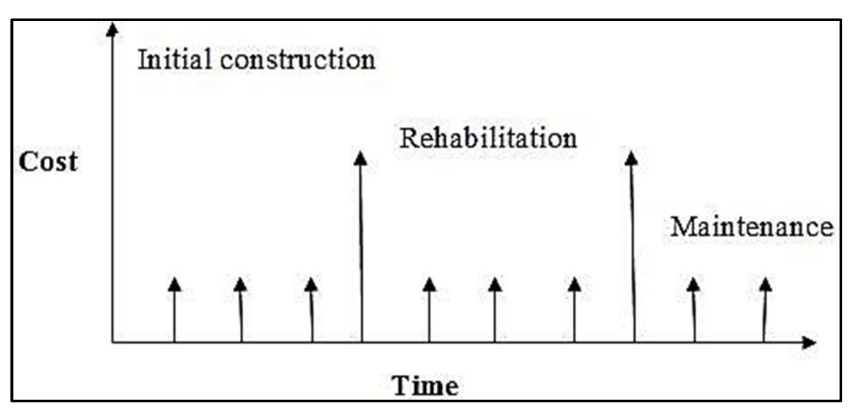

Figure 5. Life cycle analysis in pavement management.

\section{Acknowledgements}

We would like to express our special thanks to Dr. Zhao for search library databases in prestigious journals and editors of this article.

\section{References}

[1] Newcomb, Dave, and Larry Scofield, (2003), "Quiet Pavements Raise the Roof in Europe," Hot Mix Asphalt Technology, National Asphalt Pavement Association.

[2] Reyff, James, et al., (2002),. I-80 Davis OGAC Pavement Noise Study: Traffic Noise Levels Associated With an Open Grade Asphalt Concrete Overlay. Prepared for California Department of Transportation by Illingworth \& Rodkin, Inc., Sacramento, CA, December 1.

[3] Brown, E. R., (1993),. Experience with Stone Mastic Asphalt in the United States, Report No. 93-4, National Center for Asphalt Technology, Auburn University, Alabama.

[4] Design and Construction of Stone Matrix Asphalt Mixtures, (1998), Report No. 425, National CooperativeHighway Research Program, Transportation Research Board.

[5] Hughs, C., (1999), Designing and Constructing SMA Mixtures - State-of-the-Practice, QIP 122, National Asphalt Pavement Association, Lanham, Maryland.

[6] Nunn, M. E., A. Brown, D. Weston and J. C. Nicholls, (1997), Design of long-life flexible pavements for heavy traffic, Report No. 250, Transportation Research Laboratory, Berkshire, United Kingdom.

[7] Brown, S. F., W. S. Tam, and J. M. Brunton, (1987), Structural Evaluation and Overlay Design: Analysis and Implementation. Proc., Sixth International Conference on the Structural Designof Asphalt Pavements, Vol. 1, Ann Arbor, Mach, pp. 1013-1028.

[8] Hyun Jong Lee 'Jung Hun Lee, HeeMun Park, (2005), Performance evaluation of high modulus asphalt mixtures for long life asphalt pavements, Department of Civil and Environmental Engineering, Sejong University, Seoul, Republic of Korea.

[9] Jim Huddleston, P. E, Mark Bencher, Ph.D., P. E, David Newcomb, Ph.D., P. E, (2004), Asphalt Pavement Alliance, Perpetual Pavement.
[10] David Newcomb, Richard Willis, David Timm, (2010), Perpetual Asphalt Pavements in America.

[11] Advanced Asphalt Technologies (AAT), LLC. , (2007), Developing a Plan for Validating an Endurance Limit for HMA Pavements. Draft Executive Summary. National Cooperative Highway Research Program Project 9-44. Transportation Research Board. Washington, DC.

[12] Al-Qadi, I. L., H. Wang, P. J. Yoo, and S. H. Dessouky. , (2008), Dynamic Analysis and In-situ Validation of Perpetual Pavement Response to Vehicular Loading. Paper submitted to Transportation Research Board Annual Meeting. Transportation Research Board. Washington, DC.

[13] Liao, Y., (2007), Viscoelastic FE modeling of asphalt pavements and its applications to U.S. 30 perpetual pavement. Ph.D. Dissertation, Civil Engineering Department, Ohio University, Athens, $\mathrm{OH}$.

[14] Asphalt Pavement Alliance (APA). Perpetual Pavements, (2002): A Synthesis. APA 101, Lanham, Maryland.

[15] Asphalt Pavement Alliance, (2010), I-695 - a classic example of perpetual pavement..

[16] AASHTO. AASHTO, (2002), Pavement Design Guide, American Association of State Highway and Transportation Officials, Washington, D. C.

[17] Abraham, H., (1929), Asphalts and Allied Substances: Their Occurrence, Modes of Production, Uses in the Arts and Methods of Testing, Third Edition. D. Van Nostrand Co., Inc. New York, NY.

[18] Elseifi, M. A., Al-Qadi, I. L., Yoo, P. J., and Janajreh, I. , (2005), Quatification of pavement Damage Caused by Dual and Wide-Base Tires, Journal of the Transportation Research Board No. 1940, pp 125-135, National Research Council, Washington, D. C.

[19] Elseifi, M. A.; Al-Qadi, I. L.; Yoo, P. J., (2006), Viscoelastic Modeling and Field Validation of Flexible Pavements, ASCE Journal of Engineering Mechanics, Vol. 132 No. 2, pp 172178.

[20] Instrumentation for Flexible Pavements-Field Performance of Selected Sensors, (1992).

[21] Sang-Soo Kim, Shad Sarggand, Teruhisa Masada, and Jaime Hernandez, (2010), Ohio Department of Transportation Office of Research and Development and the United States Department of Transportation Federal Highway Administration, State Job Number 4377046.

[22] Liao, Y., Sargand, S. M., Khoury, I. S., and Harrigal, A., (2007), In-Depth Investigation th of Premature Distresses of Four Ohio SHRP Test Road Sections," 86 TRB Annual Meeting (CD-ROM), Transportation Research Board, National Research Council, Washington, D. C.

[23] Masada, T., (2007), Laboratory Characterization of Materials and Data Management for Ohio-SHRP Project (U.S. 23), Report No. FHWA/ OH-2001/07, Department of Civil Engineering, Ohio University, Athens, Ohio.

[24] Masada, T., Sargand, S. M., and Liao, Y. , (2006), Resilient Modulus Prediction Model for Fine-Grained Soils in Ohio: Preliminary Study, International Conference on Perpetual Pavement (CDROM), Columbus, Ohio. 
[25] Sargand, S. M., Khoury, I. S., Romanello, M. T., and Figueroa, J. L., (2006), Seasonal and Load Response Instrumentation of the Way-30 Perpetual Pavement, International Conference on Perpetual Pavement (CDROM), Columbus, Ohio.

[26] Perpetual Bituminous Pavements. , (2001), Transportation Research Circular 503, Transportation Research Board, National Research Council.

[27] Jaime A. Hernandez, (2010), Evaluation of the Response of Perpetual Pavement at Accelerated Pavement Loading Facility: Finite Element Analysis and Experimental Investigation, Russ College of Engineering and Technology of Ohio University, In partial fulfillment of the requirements for the degree Master of Science,

[28] Al-Qadi, I. L., Wang, H., Yoo, P. J., \& Dessouky, S. H. (2009). Dynamic analysis and in-situ validation of perpetual pavement response to vehicular loading. Transportation Research Record: Journal of the Transportation Research Board, 2087, 29-39.

[29] Garcia, G. \& Thompson, M. R., (2008), Strain and pulse duration considerations for extended-life hot-mix asphalt pavement design. Transportation Research Record: Journal of the Transportation Research Board, 2087, 3-11.
[30] Hornyak, N., \& Crovetti, J. A., (2009), Analysis of load pulse durations for Marquette interchange instrumentation project. Transportation Research Record: Journal of the Transportation Research Board, 2094, 53-61.

[31] Loulizi, A., AL-Qadi, I. L., \& Elseifi, M., (2006), Difference between in situ flexible pavement measured and calculated stresses and strains. Journal of Transportation Engineering, ASCE, 132 (7), 574-579.

[32] Park, D., Martin, A. E., \& Masad, E., (2005), Effects of no uniform tore contact stresses on pavement response. Journal of Transportation Engineering, ASCE, 113 (11), 873-879.

[33] Rith, M., Kim, Y. K., Hong, S. J. and Lee, S. W. (2016) "Effect of horizontal loading on RCC-base composite pavement performance at heavy duty area", Construction and Building Materials, Vol. 131, pp. 741-745

[34] Zhao, Y., Alae, M. and Fu, G. (2017) "Investigation of mechanisms of top-down fatigue cracking of asphalt pavement", Road Materials and Pavement Design, DOI: 10.1080/14680629.2017.1303394. pp. 